\title{
Potential Predictability of U.S. Summer Climate with "Perfect" Soil Moisture
}

\author{
Fanglin Yang \\ GEST/UMBC, Climate and Radiation Branch, Laboratory of Atmospheres, NASA Goddard \\ Space Flight Center, Greenbelt, Maryland \\ Arun Kumar \\ Climate Prediction Center, National Centers for Environmental Prediction, Washington D.C. \\ K.-M. Lau \\ Laboratory of Atmospheres, NASA Goddard Space Flight Center, Greenbelt, Maryland
}

\begin{abstract}
The potential predictability of surface-air temperature and precipitation over the United States continent was assessed for a GCM forced by observed sea surface temperatures and an estimate of observed ground soil moisture contents. The latter was obtained by substituting the GCM simulated precipitation, which is used to drive the GCM's land-surface component, with observed pentad-mean precipitation at each time step of the model's integration. With this substitution, the simulated soil moisture correlates well with an independent estimate of observed soil moisture in all seasons over the entire US continent. Significant enhancements on the predictability of surface-air temperature and precipitation were found in boreal late spring and summer over the US continent. Anomalous pattern correlations of precipitation and surface-air temperature over the US continent in the June-July-August season averaged for the 1979-2000 period increased from 0.01 and 0.06 for the GCM simulations without precipitation substitution to 0.23 and 0.31 , respectively, for the simulations with precipitation substitution. Results provide an estimate for the limits of potential predictability if soil moisture variability is to be perfectly predicted. However, this estimate may be model dependent, and needs to be substantiated by other modeling groups.
\end{abstract}

Corresponding author address:

Fanglin Yang, Climate and Radiation Branch, Code 913, NASA Goddard Space Flight Center, Greenbelt, MD 20771.

E-mail: fyang@climate.gsfc.nasa.gov

To be submitted to : Journal of Hydrometeorology 


\title{
Potential Predictability of U.S. Summer Climate with "Perfect" Soil
}

\section{Moisture}

\author{
Fanglin Yang \\ GEST/UMBC, Climate and Radiation Branch, Laboratory of Atmospheres, NASA Goddard \\ Space Flight Center, Greenbelt, Maryland
}

Arun Kumar
Climate Prediction Center, National Centers for Environmental Prediction, Washington D.C.

K.-M. Lau

Laboratory of Atmospheres, NASA Goddard Space Flight Center, Greenbelt, Maryland

Corresponding author address:

Fanglin Yang, Climate and Radiation Branch, Code 913, NASA Goddard Space Flight Center, Greenbelt, MD 20771.

E-mail: fyang@climate.gsfc.nasa.gov 


\section{ABSTRACT}

The potential predictability of surface-air temperature and precipitation over the United States continent was assessed for a GCM forced by observed sea surface temperatures and an estimate of observed ground soil moisture contents. The latter was obtained by substituting the GCM simulated precipitation, which is used to drive the GCM's land-surface component, with observed pentad-mean precipitation at each time step of the model's integration. With this substitution, the simulated soil moisture correlates well with an independent estimate of observed soil moisture in all seasons over the entire US continent. Significant enhancements on the predictability of surface-air temperature and precipitation were found in boreal late spring and summer over the US continent. Anomalous pattern correlations of precipitation and surface-air temperature over the US continent in the June-July-August season averaged for the 1979-2000 period increased from 0.01 and 0.06 for the GCM simulations without precipitation substitution to 0.23 and 0.31 , respectively, for the simulations with precipitation substitution. Results provide an estimate for the limits of potential predictability if soil moisture variability is to be perfectly predicted. However, this estimate may be model dependent, and needs to be substantiated by other modeling groups. 


\section{Introduction}

It is well known that tropical sea-surface temperature (SST) anomalies have substantial influence on the climate variability over North Pacific and North America in boreal winter through teleconnections (e.g., Wallace and Gutzler 1981). Results from many atmospheric general circulation models (GCM) forced by observed SSTs have shown potential predictability of North American winter climate (e.g., Kumar and Hoerling 1998; Trenberth et al. 1998; Shukla et al. 2000). During boreal summer, however, the influence of tropical SSTs on mid-latitude climate variability is weak, and is primarily limited to the zonal mean component of the extratropical height field (Schubert et al. 2002). Though a few studies have found that SST anomalies outside of the tropics might be of some predictive value (e.g., Ting and Wang 1997; Lau et al. 2003), a robust causal link between SST anomalies and the US summertime climate is yet to be established. The impact of SSTs is often blurred due to local processes and feedbacks, such as those associated with changes in low-level jet streams and ground soil moisture contents. The influence of soil moisture on precipitation and surface temperature has long been noticed, and is drawing even wider attention in recent years (e.g., Delworth and Manabe 1989; Atlas et al. 1993; Wang and Kumar 1998; Fennessy and Shukla 1999; Hong and Kalnay 2000; Koster et al. 2000; Schlosser and Milly 2002; Koster and Suarez 2001, 2003; Kanamitsu et al. 2003; Mo 2003).

Ground soil moisture content is primarily determined by ground water holding capacity, precipitation, runoff and evaporation (Delworth and Manabe 1989; Koster and Suarez 2001). In turn, soil moisture affects surface-air temperature and humidity by modifying the release of latent and sensible heat fluxes, and consequently affecting atmospheric circulation and precipitation. The processes involves many feedbacks, and is so complicated that often it is impossible to identify the cause and effect from the analysis of observational records alone. To 
circumvent this shortcoming, atmospheric GCMs have been used by many authors to understand the problem.

So far, there have been two major kinds of GCM studies. The first kind treated soil moisture as a boundary condition problem. Either model generated or idealized soil moisture anomalies were specified and maintained during model integrations to study the impact of soil moisture anomalies on the simulations of observed flood and drought conditions (e.g., Atlas et al. 1993; Hong and Kalnay 2000), or on the interannual variability of model-generated precipitation and/or surface temperature (e.g., Koster and Suraez 1995; Koster et al. 2000; Dirmeyer 2000). No feedback processes associated with soil moisture were included. The second kind treated soil moisture as an initial value problem. These studies examined how initial soil moisture anomalies, once initialized, affect the predictability of precipitation and/or surface temperature. The feedbacks between soil moisture and the atmospheric conditions were included. Often, the predictability of soil moisture itself (or soil-moisture memory) was also investigated. Most of the studies relied on idealized model-generated soil moisture anomalies (e.g., Wang and Kumar 1998; Schar et al. 1999; Schlosser and Milly 2002). Attempts have also been made to initialize the models with more realistic soil moisture anomalies, either by using soil-moisture analyses (Fennessy and Shukla 1999; Kanamitsu e al. 2003) or by performing spin-up simulations for which observed atmospheric conditions were used to force the model's land-surface component before formal predictions start (Koster and Suraez 2003). These studies emphasized the importance of initial soil moisture anomalies. The degree to which the initialization can enhance the predictability of summertime precipitation and temperature is mixed, varying among models and with locations.

The potential predictability in association with observed SST anomalies have been explored in-depth using GCM results from AMIP-type experiments (e.g., Kumar and Hoerling 
1998; Straus et al. 2003). A similar investigation on the predictability in association with "observed" soil moisture anomalies have not been attempted, primarily because of the lack of global-scale long-term observations of soil moisture. Various ongoing land data assimilation system (LDAS) are filling this gap by running retrospectively and in near real-time the LDAS (e.g., Mitchell et al. 1999; Cosgrove et al. 2003). Satellite observations have also started to produce soil moisture estimations. However, there are inherent problems when independent soil moisture observations or analyses are used as initial or boundary conditions for GCM experiments. A variety of land-surface models are now being used by different GCMs, and often they are also different from those used in land data assimilation systems. These differences cause incompatibility in soil types, layers, and field capacity, and consequently different definitions of "dry" and "wet" conditions in the models. For example, Fennessy et al. (2000) used the soil moisture analysis of Huang et al. (1996) as initial conditions to perform near realtime seasonal prediction by the Center for Ocean-Land-Atmosphere Studies GCM. They found several adjustments have to be made with the soil moisture data for compatibility.

In this study, we propose first a simple method to generate GCM soil moisture that is fairly realistic. We substitute the model simulated precipitation with observed precipitation during model integrations to force the model's land-surface component. By doing so the incompatibility issue is avoided, and the feedbacks between soil moisture and the atmospheric conditions are also retained. Results show that the simulated soil moisture matches well with the Huang et al. (1996) analysis in all seasons. Then, the potential predictability of precipitation and surface-air temperature over the continental United States in boreal summer is explored using a set of ensemble GCM simulations, which are forced by observed SSTs and the almost "perfect" ground soil moisture contents. 
A brief outline of this paper is as follows. Section 2 describes the National Centers for Environmental Prediction (NCEP) GCM and the observed SSTs and precipitation used to force the GCM. Given the fact that observational precipitation analyses are often presented as daily, pentad or monthly means, a choice has to be made of the kind of precipitation data to use. Following a perfect model approach, different options are evaluated in section 3 . It is found that using pentad mean precipitation can reproduce well the land-surface features that the NCEP GCM simulates when no alteration of precipitation is made. Section 4 compares the GCM simulated soil moisture with precipitation assimilation with an observational analysis. The potential predictability of US summertime climate is examined in section 5 . The conclusions and discussions are presented in section 6.

\section{Model and Data Descriptions}

The atmospheric GCM used in this study is the NCEP seasonal forecast model. It has been described in detail by Kanamitsu et al. (2002). In brief, the GCM has a spectral triangular truncation at wave number 42 , and has 28 levels in the vertical direction. The horizontal grid spacing is approximately $3^{\circ}$ in latitude and longitude. In the model, surface temperature is predicted and governed by a surface energy budget equation. Surface momentum, sensible and latent fluxes are parameterized using the Monin-Obukov similarity profile (Miyakoda and Sirutis 1986). A two-layer soil model (Mahrt and Pan 1984) is used to predict soil moisture fraction, soil temperature and canopy water content. The top layer extends from the surface to $10 \mathrm{~cm}$, and the deep layer extends from 10 to $200 \mathrm{~cm}$. Vegetation type and cover and soil type are taken from the Simple Biosphere model climatology (Dorman and Sellers 1989).

For all GCM experiments we present here, the model was forced by the observed monthly mean SSTs for the period from 1979 through 2000 (Smith et al. 1996). For the 
experiments described in section 4 in which the observed precipitation was assimilated to replace model predicted precipitation, we used the Experimental Global Precipitation Climatology Project (GPCP) Pentad Precipitation Analysis, created and maintained at NCEP (Pingping Xie, personal communication). This dataset was defined by merging gauge and satellite observations, and has a resolution of $2.5^{\circ}$ latitude by $2.5^{\circ}$ longitude. At the time we carried out these experiments, this dataset was the only one available that has a fine temporal resolution, covers the globe and extends back to 1979. More recently, Huffman et al. (2001) produced a onedegree daily-mean precipitation dataset. In section 3 , in the context of a perfect model approach, we demonstrated that results drown from this study are not biased because of the use of the pentad-mean precipitation instead of other types of precipitation with higher temporal resolutions.

\section{Choice of Mean Precipitation for Assimilation - A Perfect Model Assessment}

Ideally, the best choice for GCM precipitation assimilation is to have an observational precipitation dataset whose temporal resolution matches the time step of the model's landsurface physics. However, observational precipitation analyses are often presented as daily, pentad or monthly means. Are the modeled ground soil moisture contents and surface climate affected by the use of time-averaged precipitation instead of the precipitation produced by the model at each time step? We assess this impact from a set of comparative GCM experiments.

We performed first a 22-year simulation for the 1979-2000 period forced by observed SSTs, a standard AMIP-type simulation. We refer this simulation hereinafter as $C n t l$. Daily mean precipitation was saved during the $C$ ntl run. Pentad and monthly means were subsequently derived. Then, three more GCM experiments were performed for the 1979-2000 period starting from the same single initial condition and forced by the same SSTs, except that for the landsurface component of the GCM the saved daily, pentad and monthly mean precipitation were 
inserted into the GCM to replace the model predicted precipitation (referred to as Daily, Pentad and Monthly experimental runs, respectively). To elaborate, for instance, the Pentad run was carried out in such a way that the pentad precipitation derived from the Cntl run was divided equally and inserted into the soil moisture budget equation at each model physical step to update canopy water content, runoff and soil moisture fraction. The precipitation predicted by the model itself was ignored. The insertion is made only if the model predicted precipitation is in liquid phase, that is to say, snow is still predicted by the model itself. For illustration, the daily, pentad and monthly precipitation averaged over the US continent for 1979 are plotted in Figure 1.

The focus of this study is on summertime surface climate in monthly to seasonal time scales. To understand to what extent the substitution of modeled precipitation with timeaveraged precipitation replicates the soil moisture evolution, we compared a few land and nearsurface properties from the experimental runs (Daily, Pentad, and Monthly) with those from the control run $(\boldsymbol{C n t l})$.

Shown in Figure 2 are percent differences of the top-layer $(0-10 \mathrm{~cm})$ soil moisture content and surface-air temperature in July averaged for the 1979-2000 period between the experimental runs and the control run. Figure 3 are local correlations for the 22-year period in July. For all three experimental runs, the biases in soil moisture content and surface-air temperature are less than $10 \%$ everywhere over the US continent. Local correlations are generally larger than 0.9 for soil moisture and larger than 0.8 for surface-air temperature. The results from the Pentad run are rather close to the Daily run. Larger biases are found for the Monthly run. For other months in the warm season, we found similar results (not shown). For the cold season, even though the simulated soil moisture contents from the experimental runs still match rather well with that from the control run, surface-air temperature shows almost no correlation, indicating much stronger dynamical control of the atmosphere in winter than in summer. 
These tests indicate that monthly mean statistics of the modeled land and near-surface properties in summer have not been seriously altered because of the use of time-averaged precipitation as forcing for the GCM land-surface component. In section 4, observed pentad mean precipitation will be used to force the GCM for our investigation of the predictability of US summer climate. Based on the comparisons presented in this section we feel confident that our results are not biased because of the choice of the pentad mean precipitation.

\section{4. “Perfect" Soil Moisture from Precipitation Assimilation}

Starting from different atmospheric and land-surface initial conditions, three GCM simulations were performed with the same observed monthly SSTs over the ocean and the observed GPCP pentad-mean precipitation over land for the $1979-2000$ period. We refer this set of simulations as obs_rain. For comparison and consistency, two additional runs similar to the Pentad run in section 3 were performed starting from different atmospheric and land-surface initial conditions. We refer this set of three simulations forced by model predicted pentad-mean precipitation as gcm_rain. The simulated soil moisture contents from the two sets of simulations were then evaluated against observations to measure the improvement in soil moisture simulation by precipitation assimilation. All calculations thereinafter are based on ensemble means of the GCM simulations.

Currently, there are still no global and long-term observations, either on the ground or from satellites, of soil moisture contents suitable for climate study. For validation we rely on a model-based soil moisture analysis over the US continent conducted routinely at NCEP, which is based on the work of Huang et al. (1996). This analysis is performed with a one-layer $(0-160 \mathrm{~cm})$ soil moisture model that computes the water budget in the soil and is forced by observed monthly temperature and precipitation. Huang et al. (1996) showed that their model analysis compared 
well with the soil moisture observations in Illinois in terms of climatology and interannual variation. The analysis has been used widely for climate diagnosis and prediction (e.g., van den Dool et al. 2003; Mo 2003).

The GCM consists of a two-layer soil model, with the top layer extends down to $10 \mathrm{~cm}$ and the lower layer from $10 \mathrm{~cm}$ to $200 \mathrm{~cm}$. We derived the GCM soil moisture content for the top $160 \mathrm{~cm}$ by linear scaling. Figure 4 compares the $1979-2000$ climate means of soil moisture content in the top $160 \mathrm{~cm}$ over the US continent in boreal summer months (June, July and August, respectively) between the GCM results and the Huang et al. analysis. Forced by the GCM's own pentad-mean precipitation (gcm_rain runs), the model is too wet over the northwestern states and two dry over the central and southern states from Iowa down to Louisiana and eastern Texas. These biases are greatly reduced in the obs_rain runs in which the observed GPCP precipitation was assimilated. Over the central to southeastern states, the model suffered from moderate wet biases in the gcm_rain runs and moderate dry biases in obs_rain runs.

Figure 5 presents the local correlations of soil moisture content between model simulations and the Huang et al. analysis for the 1979-2000 period. For the gcm_rain runs, the model shows no skill in soil moisture simulations, with a few exceptions over the southeastern states, the northern part of the Great Plains and the southwestern states. For the runs forced by the observed GPCP precipitation (obs_rain runs), the correlations between the model predicted soil moisture and the analysis are generally larger than 0.6 over the continent.

The result indicates that even though ground soil moisture contents are controlled by many parameters and physical processes such as air and ground temperatures, runoff, soil and vegetation types, precipitation and evaporation, and the feedbacks among the processes (Delworth and Manabe 1988; Koster and Suarez 2001), it is quite effective simply substituting 
the modeled precipitation with observations if the goal is to obtain a better soil condition to force the atmosphere. We next investigate the potential predictability of US surface climate simulated by the NCEP GCM, given the so-derived "perfect" soil moisture contents. This is analogous to the traditional GCM investigation of predictability associated with prescribed SST anomalies (e.g., Kumar and Hoerling 1998; Straus et al. 2003).

\section{Potential Predictability of US Surface Climate with "Perfect" Soil Moisture}

Here the measure of predictability is defined as the contemporary correlations of monthly mean surface-air temperature and precipitation between model simulations and observations. For observations, we use monthly mean precipitation derived from the GPCP daily precipitation (Huffman et al. 2001), and monthly mean surface-air temperature from the global network of surface observations, the Climate Anomaly Monitoring System (CAMS), maintained at NCEP (Ropelewski et al. 1986). Figure 6 presents the correlation maps of monthly mean surface-air temperature over the US continent between the CAMS observation and the two sets of GCM experiments, gcm_rain and obs_rain, respectively, in the three boreal summer months for the 1979-2000 period. Correlation maps for precipitation are presented in Figure 7. If we regard correlations larger than 0.4 as skillful (at about the $94 \%$ significance level for a student-t test), the GCM has skills in predicting the surface-air temperature over only a few states when forced by the model's own precipitation (Figures 6a-c), such as those over Idaho in June and July and over Georgia and Alabama in July. When forced by the observed GPCP precipitation, the model's prediction skills are enhanced in general over many states (Figures 6d-f). The areas with the biggest improvement are found over Montana, the Great Plains, the Mississippi Valley, Texas and New Mexico. 
For precipitation (Figure 7), when forced by the model predicted precipitation, the model has certain prediction skills in the northwest in June and July and in the southeast in July. Over many regions, the correlations are even negative (Figures $7 \mathrm{a}-\mathrm{c}$ ). When forced by the observed GPCP precipitation, the skills are improved over the entire US continent in general, although in June and July the model became less skillful over a few states over the northwest.

The prediction skills described here are the potential predictability of the NCEP GCM, in the sense that when perfect boundary conditions of SSTs and soil moisture contents were used to force the model. Given the chaotic feature of the atmospheric circulation, which only to a certain extent is constrained by the specification of soil moisture, the prediction skill is fundamentally limited. With the foreknowledge of soil moisture in addition to SSTs, the enhancement in the predictions of precipitation and temperature is not uniform in space and time. Koster et al. (2000) demonstrated that for precipitation the enhancement can be detected only in the transition zones between dry and humid climates, where evaporation responds strongly to soil moisture changes and the variation in evaporation itself is also large enough to affect the overlying atmosphere. Our results tend to agree with their findings.

To see the seasonal dependence of the model's prediction skills, we computed the mean correlations shown in Figures 5-7 over the entire US continent and for all 12 months, and plotted in Figure 8 the spatial mean correlations for soil moisture, surface-air temperature and precipitation, respectively. The model's simulation skill in soil moisture is greatly enhanced in all months when forced by the observed precipitation. The correlations for soil moisture are raised from almost below 0.2 for the gcm_rain runs to about 0.6 for the obs_rain in all months. For precipitation and surface-air temperature, enhanced simulation skills are found only in late spring and summer months. The correlations are raised by about 0.1 for precipitation and by up to 0.3 for surface-air temperature. 
We computed further the pattern correlations over the US continent for June-July-August averaged anomalies of soil moisture, precipitation and surface-air temperature between model simulations and the corresponding observations for the years from 1979 through 2000 (Figure 9). With precipitation assimilation (cross bars in Figure 9), the anomalous pattern correlations for the three variables are positive in all years. Consistent with the mean temporal correlations shown in Figure 8, the most significant improvement is found for soil moisture. The simulations for precipitation and surface-air temperature are also improved considerably.

\section{Conclusions and Discussions}

It is still a big challenge for current atmospheric GCMs to simulate accurately atmospheric precipitation and hence the soil moisture content. Previous studies (e.g., Fennessy and Shukla 1999; Kanamitsu e al. 2003; Koster and Suarez 2003) have demonstrated that GCMs initialized with realistic soil moisture contents can improve the prediction skills of US summer climate over certain regions. The potential predictability associated with soil moisture as a boundary forcing instead of an initial value problem has not been explored because of the scarcity of soil moisture observations.

In this study, the potential predictability of precipitation and surface-air temperature over the US continent in boreal summer is estimated using the NCEP operational seasonal forecast model with precipitation assimilation and with the observed SSTs as boundary forcing over the oceans. The observed GPCP pentad-mean precipitation was assimilated into the model during model integrations to substitute the model predicted precipitation as input to the land-surface component of the GCM. Soil moisture contents simulated by the GCM with this simple precipitation substitution match well with the Huang et al. (1996) soil moisture analysis over the US continent in all seasons in terms of climate mean, and almost "perfectly" well in terms of 
temporal and anomalous pattern correlations. The potential prediction kills of precipitation and surface-air temperature are also greatly improved in late spring and summer months over many states of the continent. Averaged for all years, the anomalous pattern correlations shown in Figure 9 for June-July-August mean precipitation and surface-air temperature are 0.01 and 0.06 , for the runs without precipitation assimilation, and are raised to 0.23 and 0.31 , respectively, for the runs with precipitation assimilation. This indicates that even though the potential predictability of US summer climate associated with SST anomalies is low, better prediction skills can still be achieved with improved modeling of ground soil moisture contents.

Now the question is how to improve the simulation of soil moisture in GCMs. One way is to initialize the GCM with realistic soil moisture contents (e.g., Fennessy and Shukla 1999; Schlosser and Milly 2002; Kanamitsu e al. 2003; Koster and Suarez 2003). But the persistence or memory of soil moisture anomalies is usually small in spring and summer over the US continent (Wang and Kumar 1998; Schlosser and Milly 2002). Schlosser and Milly found for the Geophysical Fluid Dynamics Laboratory climate model the predictability timescale of soil moisture measured as e-folding decaying time is about 2 weeks or less in mid-latitudes during summer. Seasonal prediction skills of US summer climate with soil moisture anomalies treated as an initial value problem is limited because of the short memory of soil moisture in summer and the inability of current GCMs in simulating precipitation in accuracy. Results from previous studies showed that the degree to which the initialization can enhance the predictability of summertime precipitation and temperature is limited and mixed, varying among models and with locations.

In this study we treat soil moisture as a boundary value problem, and demonstrated the appreciable prediction skills of US summer climate. Similar studies can be carried out using soil moisture product from land data assimilation systems (e.g., Mitchell et al. 1999; Cosgrove et al. 
2003) to understand better the potential predictability of US summer climate for other GCMs. However, this approach is not practical for operational forecast because we do not know soil moisture or precipitation beforehand. On the other hand, given the strong dependence of soil moisture on precipitation as witnessed through this study, it might be helpful to apply bias corrections, in terms of not only mean but also spatial patterns, on GCM predicted precipitation during real-time seasonal forecast based on antecedent statistical relations between model predicted precipitation and observations. The reduction in precipitation bias might lead to improved simulation of soil moisture, and possibly better prediction skills of surface-air temperature and, in turn, precipitation itself. This kind of model-output-statistics (MOS) adjustment has been applied to, for instance, surface winds, for the dynamical forecast of tropical SSTs, and proved to be effective in improving the forecast skill of SSTs (Ji et al. 1994). A proper soil moisture initialization combined with precipitation MOS correction might enhance further the seasonal forecast skills of US summer climate.

$\therefore$ Finally, we note that our analysis only provides an estimate for the potential predictability related to the interannual variability of the soil moisture anomalies. Such estimates can be easily biased by the GCM characteristics, and remain to be substantiated by other modeling systems. Another factor that might have influenced our estimates for the potential predictability is the ensemble size of three used in this study. As was shown by Kumar and Hoerling (2000), the expected level of skill depends on the ensemble size. Given the fact that the expected level of skill progressively increases with increasing ensemble size, potential predictability estimates based on larger ensembles may be slightly higher than the ones obtained in the present analysis. 


\section{References}

Atlas, R., N. Woldson, and J. Terry, 1993: The effect of SST and soil moisture anomalies on GLA model simulations of the 1998 U.S. summer drought. J. Climate, 6, 2034-2048.

Cosgrove, B. A, and co-authors, 2003: Real-time and retrospective forcing in the North American Land Data Assimilation System (NLDAS) project. J. Geophys. Res., 108, 10.1029/2002JD003118.

Delworth, T. L., and S. Manabe, 1988: The influence of potential evaporation on the variability of simulated soil wetness and climate. J. Climate, 1, 523-547.

Dirmeyer, P. A., 2000: Using a global soil wetness dataset to improve seasonal climate simulation. J. Climate, 13, 2900-2922.

Dorman, J. ., and P. J. Sellers, 1989: A global climatology of albedo, roughness and stomatal resistance for atmospheric general circulation models as represented by the Simple Biosphere Model (SB). J. Appl. Meteor., 28, 833-855.

Fennessy, M. J., J. Shukla, 1999: Impact of initial soil wetness on seasonal atmospheric prediction. J. Climate, 12, 3167-3180.

Hong, S.-Y., and E. Kalnay, 2000: Role of sea surface temperature and soil-moisture feedback in the 1998 Oklahoma-Texas drought. Nature, 408, 842-844.

Huang, J., H. M. van den Dool, K. P. Georgarakos, 1996: Analysis of model-calculated soil moisture over the United States (1931-1993) and applications to long-range temperature forecasts. J. Climate, 9, 1350-1362.

Huffman, G. J., R. F. Adler, M. Morrissey, D.T. Bolvin, S. Curtis, R. Joyce, B. McGavock, J. Susskind, 2001: Global precipitation at one-degree daily resolution from multi-satellite observations. J. Hydrometeor., 2, 36-50. 
Ji, M., A. Kumar, and A. Leetmaa, 1994: A multiseason climate forecast system at the National Meteorological Center, Bull. Am. Meteorol. Soc., 75, 569-577.

Kanamitsu, M., C.-H. Lu, J. Schemm, W. Ebisuzaki. 2003: The predictability of soil moisture and near-surface temperature in hindcasts of the NCEP seasonal forecast model. J. Climate, $16,510-521$.

Kanamitsu., M., A. Kumar, J-K Schemm, H-M H. Juang, W. Wang, F. Yang, S-Y Hong, P. Peng, W. Chen, and M. Ji, 2002: NCEP dynamical seasonal forecast system 2000. Bull. Amer. Meteor. Soc., 83, 1019-1037.

Koster, R. D., and M. J. Suarez, 1995: The relative contributions of land and ocean processes to precipitation variability. J. Geophys. Res., 100, 13775-13790.

Koster, R. D., and M. J. Suarez, 2001: Soil moisture memory in climate models. J. Hydrometeor., 2, 558-570.

Koster, R. D., and M. J. Suarez, 2003: Impact of land surface initialization on seasonal precipitation and temperature prediction. J. Hydrometeor., 4, 408-423.

Koster, R. D., M. J. Max, and M. Heiser, 2000: Variability and predictability of precipitation at seasonal-to-interannual timescales. J. Hydrometeor., 1, 26-46.

Kumar, A., M. P. Hoerling, 1998: Annual cycle of Pacific-North American seasonal predictability associated with different phases of ENSO. J. Climate, 11, 3295-3308.

Kumar, A., M. P. Hoerling, 2000: Analysis of a conceptual model of seasonal climate variability and implications for seasonal prediction. Bull. Amer. Meteor. Soc., 81, 255-264.

Lau, K.-M., J.-Y. Lee, K.-M. Kim, and I.-S. Kang. 2003: The North Pacific as a regulator of summertime climate over Eurasia and North America. J. Climate, in press.

Mahrt, L., and H.-L. Pan, 1984: A two layer model of soil hydrology. Bound-Layer Meteor., 29, $1-20$. 
Mitchell, K., and co-authors, 1999: GCIP land data assimilation system (LADS) project now underway. GEWEX NEWS, 9, 3-6.

Miyakoda, K., and J. Sirutis, 1986: Manual of the E-physics. Available from Geophysical Fluid Dynamics Laboratory, Princeton University, P.O. Box 308, Princeton, NJ 08542.

Mo, K. C., 2003: Ensemble canonical correlation prediction of surface temperature over the United States. J. Climate, 16, 1665-1683.

Ropelewski, C. F., and M. S. Halpert, 1986: North America precipitation and temperature patterns associated with the El Niño/Southern Oscillation (ENSO). Mon. Wea. Rev., 114, $2352-2362$.

Schar, C., D. Luthi, U. Beyerle, and E. Heise, 1999: The soil-precipitation feedback: A process study with a regional climate model. J. Climate, 12, 722-741.

Schlosser, C. A., and P. C. D. Milly, 2002: A model-based investigation of soil moisture predictability and associated climate predictability. $J$. Hydrometeor., 3, 483-501.

Schubert, S. D., M. J. Suarez, P. J. Pegion, M. A. Kistler, A. Kumar, 2002: Predictability of zonal means during boreal summer. J. Climate, 15, 420-434.

Shukla, J., and and Coauthors, 2000: Dynamical seasonal prediction. Bull. Amer. Meteor. Soc., 81, 2593-2606.

Smith, T. M., R. W. Reynolds, R. E. Livezey, and D. C. Stokes, 1996: Reconstruction of historical sea surface temperature using empirical orthogonal functions. J. Climate, 9, 14031420.

Straus, D., J. Shukla, D. Paolino, S. Schubert, M. Suarez, P. Pegion, A. Kumar, 2003: Predictability of the seasonal mean atmospheric circulation during autumn, winter, and spring. J. Climate, 16, 3629-3649. 
Ting, M., and H. Wang, 1997: Summertime U.S. precipitation variability and its relation to Pacific Sea surface temperature. J. Climate., 10, 1853-1873.

Trenberth, K. E., G. Branstator, G. W. Karoly, A. Kumar, N.-C. Lau, and C. Ropelewski, 1998: Progress during TOGA in understanding and modeling global teleconnections with tropical sea surface temperatures. J. Geophys. Res., 103, 14291-14324.

van den Dool H., J. Huang, Y. Fan, 2003: Performance and analysis of the constructed analogue method applied to US soil moisture over 1981-2001. J. Geosphy. Atmos., 108 (D16), $10.1029 / 2002 \mathrm{JD} 003114$.

Wallace, J. M., and D. S. Gutzler, 1981: Teleconnections in the geopotential height field during the Northern Hemisphere winter. Mon. Wea. Rev., 109, 784-812.

Wang, W., and A. Kumar, 1998: A GCM assessment of atmospheric seasonal predictability associated with soil moisture anomalies over North America. J. Geophys. Res., 103, 2863728646. 


\section{Figure Captions}

Figure 1. Daily, pentad and monthly mean precipitation averaged over the US continent, derived from the Cntl run for 1979. Large variations of daily and pentad precipitation are superimposed on the monthly means.

Figure 2. Percent differences of the GCM simulated top-layer soil moisture content (left panels) and surface-air temperature (right panels) between the experimental runs (Daily, Pentad, and Monthly) and the control run (Cntl) in July, averaged for the1979-2000 period. Dotted lines are for negatives.

Figure 3. Local correlations of the GCM simulated top-layer soil moisture content (left panels) and surface-air temperature (right panels) between the experimental runs (Daily, Pentad, and Monthly) and the control run (Cntl) in July for the 1979-2000 period.

Figure 4. Differences in soil moisture contents in the top $160 \mathrm{~cm}$ between the GCM simulations and the Huang et al. (1996) analysis in June, July and August, averaged for the 1979-2000 period. Left panels are for the gcm_rain runs in which the GCM was forced by its own pentad-mean precipitation. Right panels are for the obs_rain runs in which the GCM was forced by the observed GPCP pentad mean precipitation. Dotted lines are for negatives.

Figure 5. Same as in Figure 4, except for local correlations. 
Figure 6. Local correlations of surface-air temperature between the GCM simulations and the CAMS observations in June, July and August averaged for the 1979-2000 period. Left panels are for the gcm_rain runs, and right panels for the obs_rain runs.

Figure 7. Local correlations of precipitation between the GCM simulations and the GPCP observations in June, July and August averaged for the 1979-2000 period. Left panels are for the gcm_rain runs, and right panels for the obs_rain runs.

Figure 8. Mean correlations between prediction and observations averaged over the entire US continent, for (a) soil moisture, (b) precipitation, and (c) surface-air temperature, as shown in Figures 5-7 except for all months. Dotted lines are for the correlations between the gcm_rain runs and observations, and bold lines are for those between the obs_rain runs and observations.

Figure 9. Pattern correlations of June-July-August mean anomalies for (a) soil moisture, (b) precipitation, and (c) surface-air temperature over the US continent from 1979 through 2000 between the NCEP GCM simulations and the observations as described in the text. Solid bars are for the gcm_rain runs for which precipitation assimilation was not applied. Cross bars are for the obs_rain runs for which the observed GPCP pentad-mean precipitation was used to force the land-surface component of the GCM. 


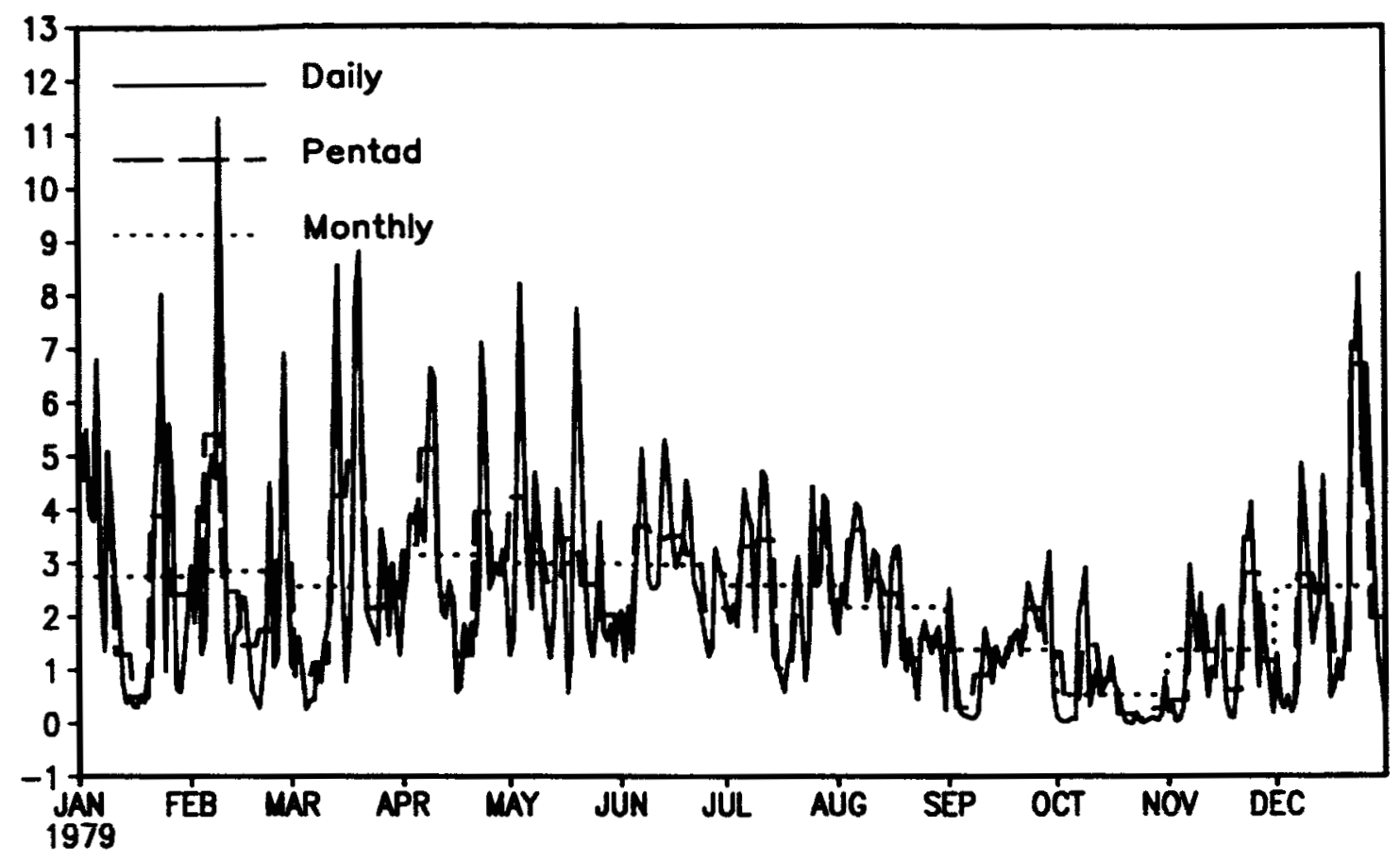

Figure 1. Averaged daily, pentad and monthly mean precipitation over the US continents, derived from the Cntl run for 1979. Large variations of daily and pentad precipitation are superimposed on the monthly means. 
(a) SM, Daily

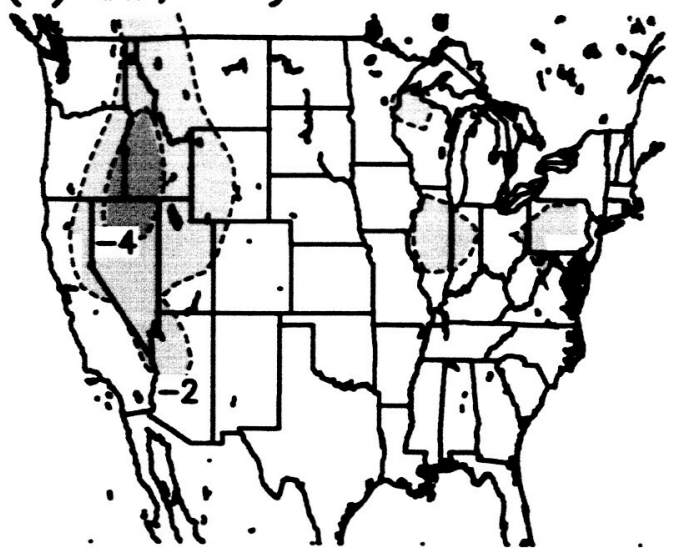

(b) SM, Pentad

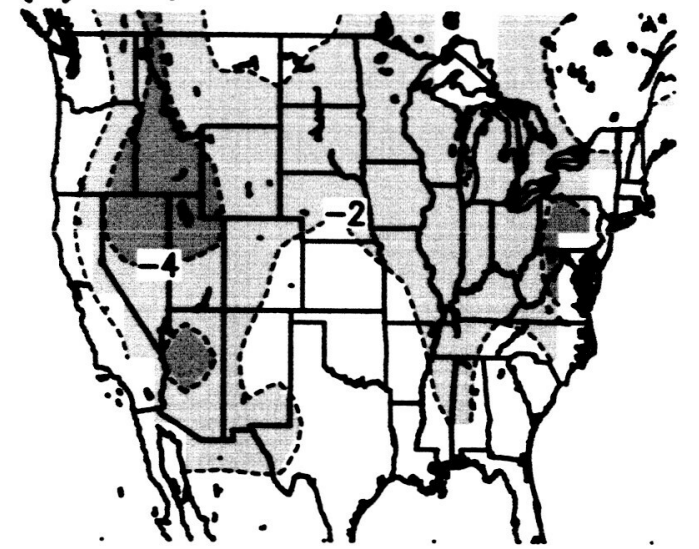

(c) SM, Monthly

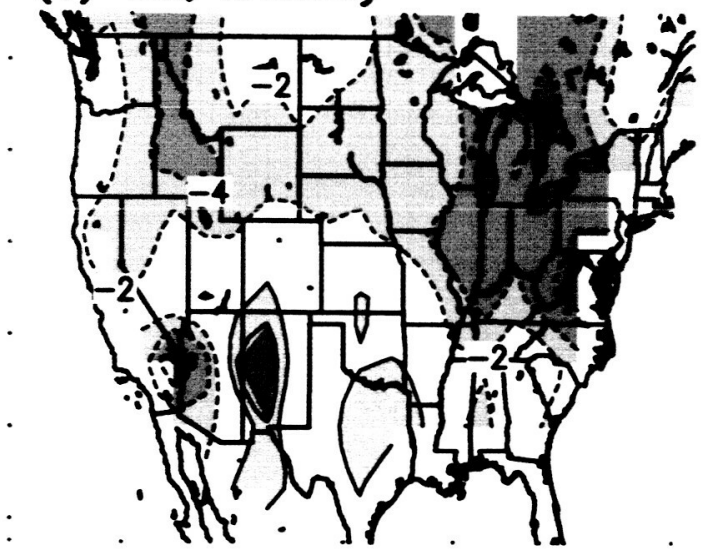

(d) Ts, Daily

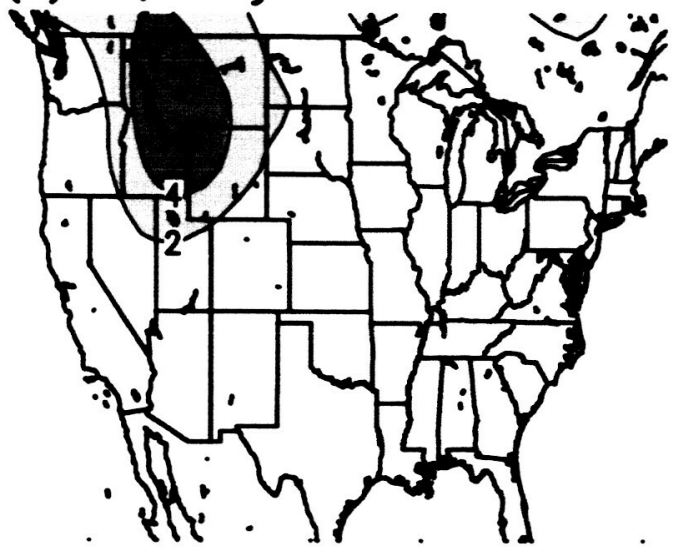

(e) Ts, Pentad

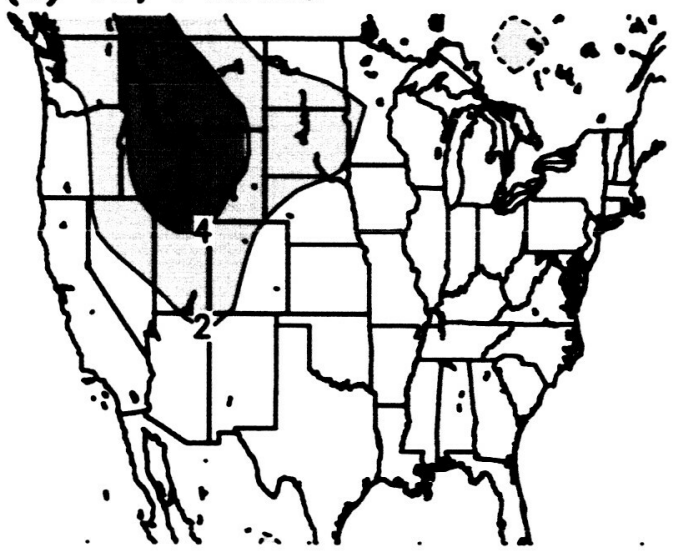

(f) Ts, Monthly

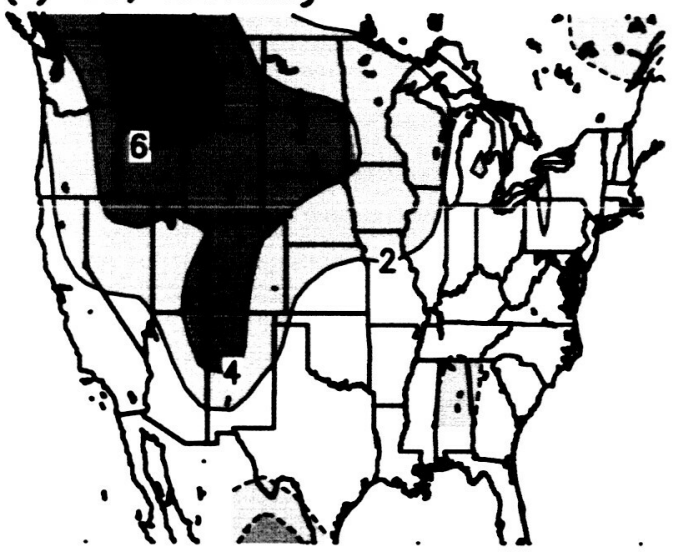

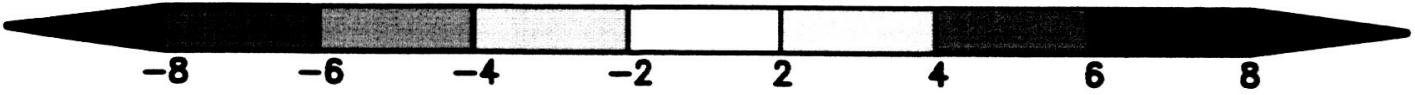

Figure 2. Percent differences of the GCM simulated top-layer soil moisture content (left panels) and surface-air temperature (right panels) between the experimental runs (Daily, Pentad, and Monthly) and the control run (Cntl) in July, averaged for the1979-2000 period. Dotted lines are for negatives. 
(a) SM, Daily

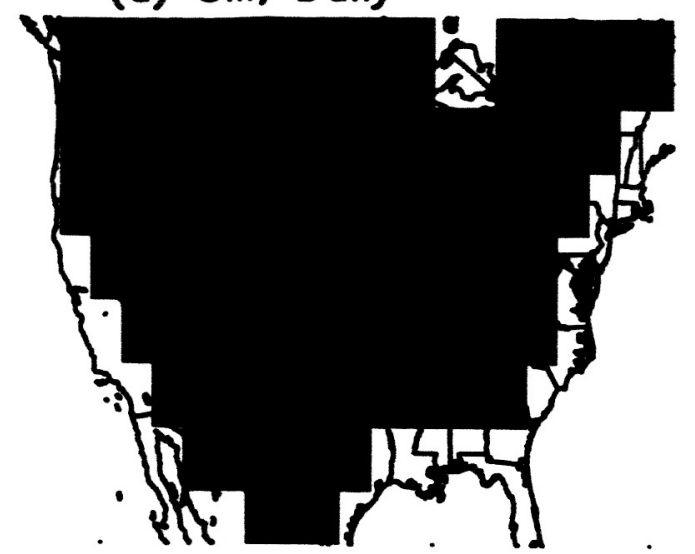

(b) SM, Pentad

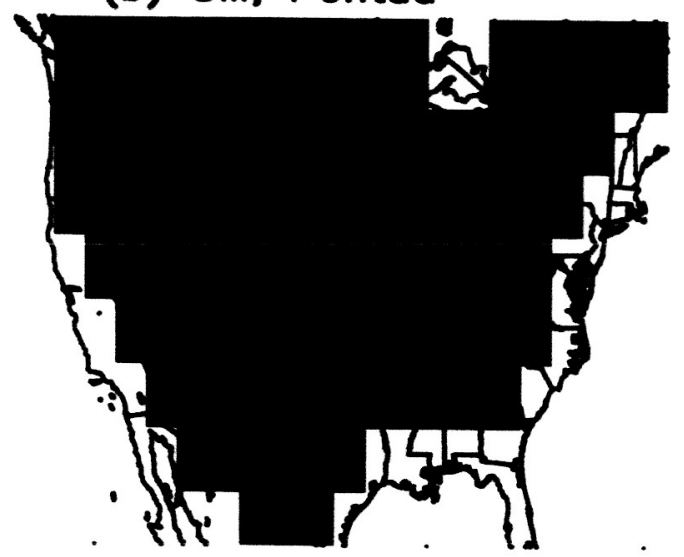

(c) SM, Monthly

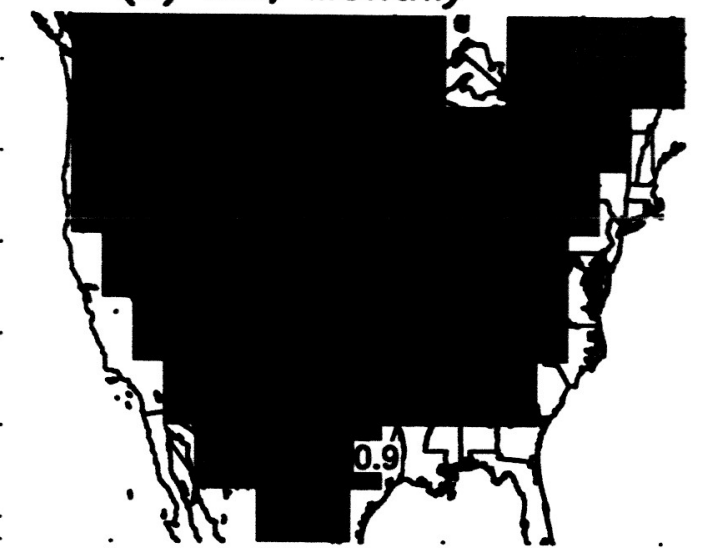

(d) Ts, Daily

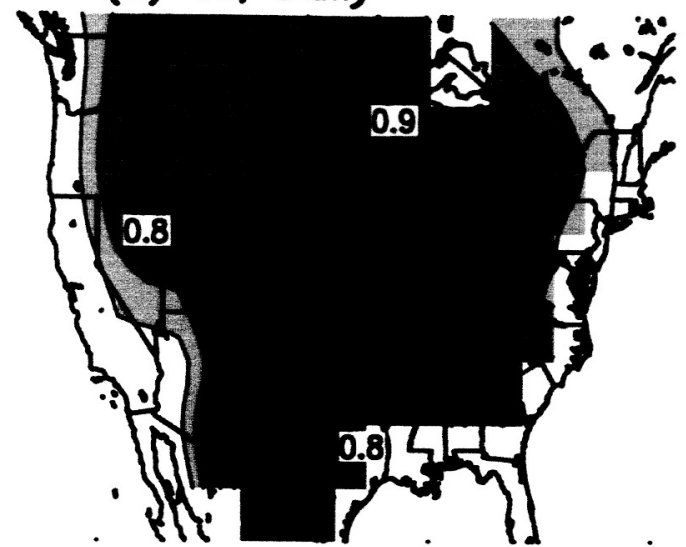

(e) Ts, Pentad

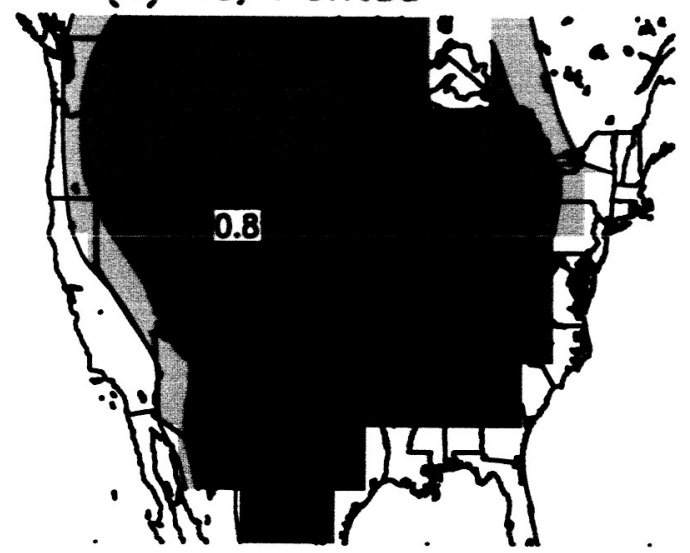

(f) Ts, Monthly

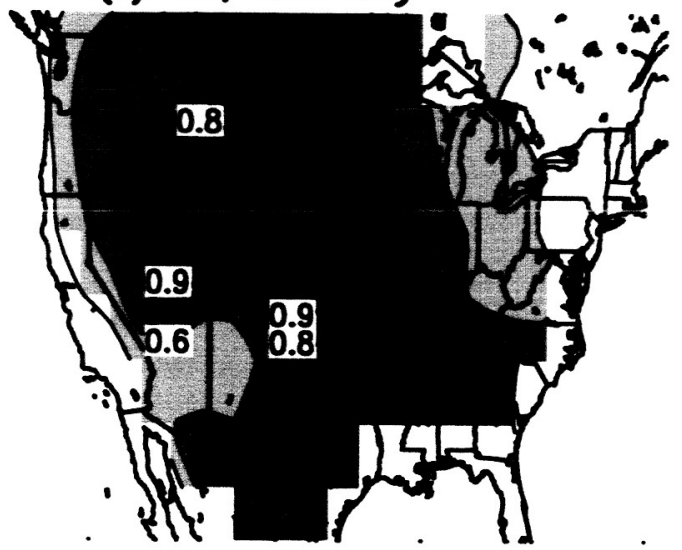

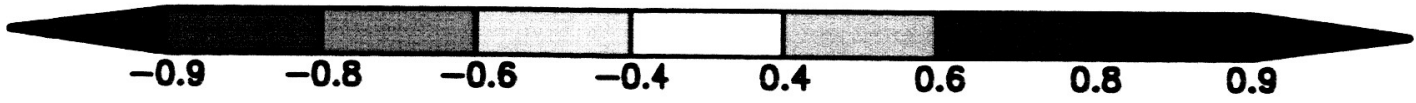

Figure 3. Local correlations of the GCM simulated top-layer soil moisture content (left panels) and surface-air temperature (right panels) between the experimental runs (Daily, Pentad, and Monthly) and the control run (Cntl) in July for the1979-2000 period. 
(a) gcm_rain, Jun

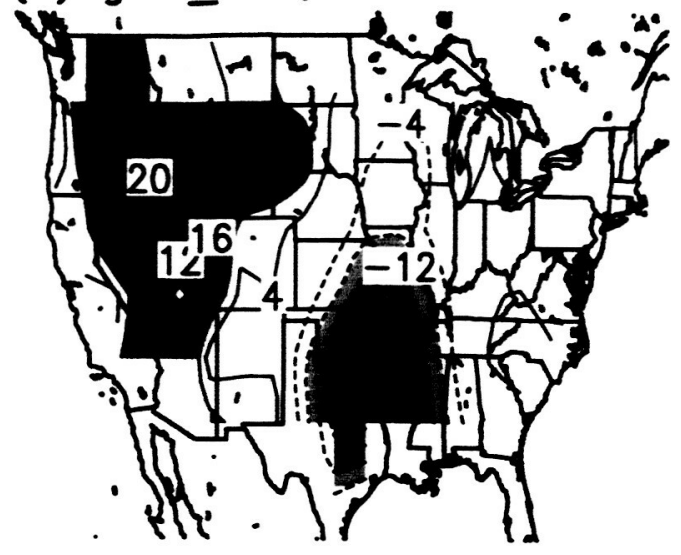

(b) gcm_rain, Jul

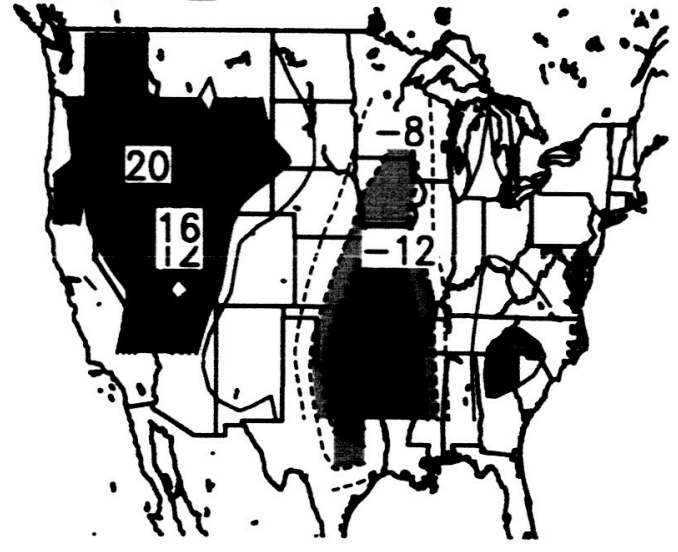

(c) gcm_rain, Aug

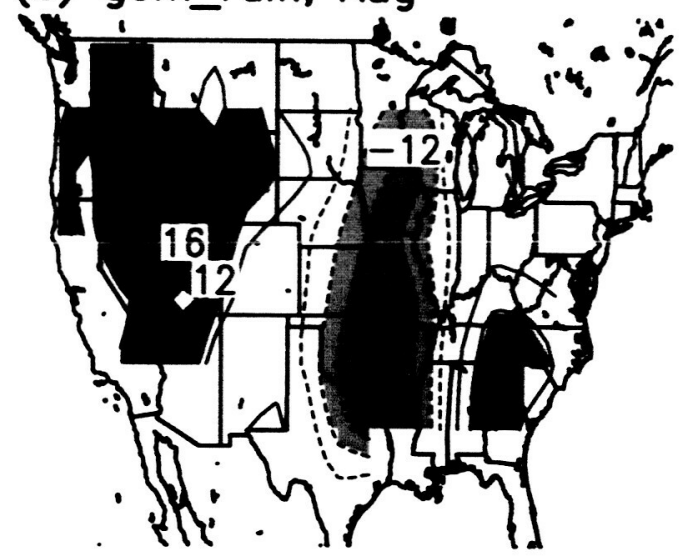

(d) obs_rain, Jun

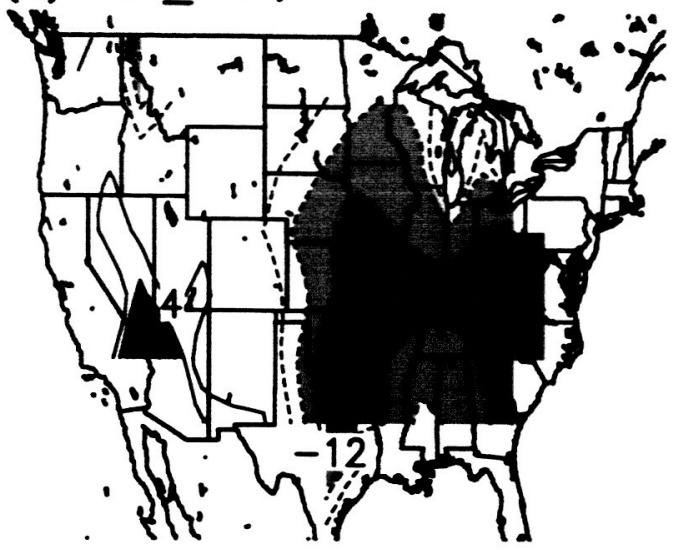

(e) obs_rain, Jul

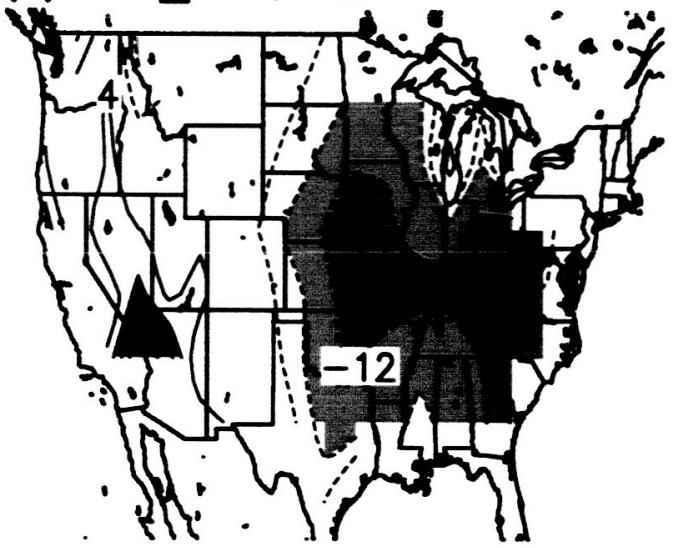

(f) obs_rain, Aug

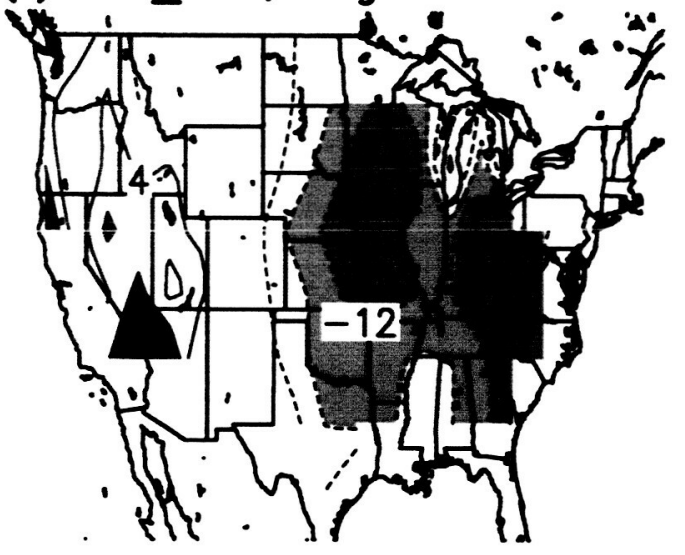

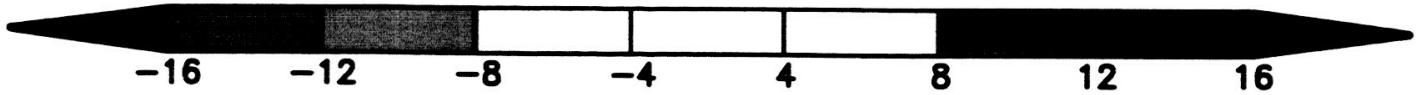

Figure 4. Differences in soil moisture contents in the top $160 \mathrm{~cm}$ of the soil between the GCM simulations and the Huang et al. (1996) analysis in June, July and August averaged for the 19792000 period. Left panels are for the gcm_rain runs in which the GCM was forced by its own pentad-mean precipitation. Right panels are for the obs_rain runs in which the GCM was forced by the observed GPCP pentad mean precipitation. Dotted lines are for negatives. 

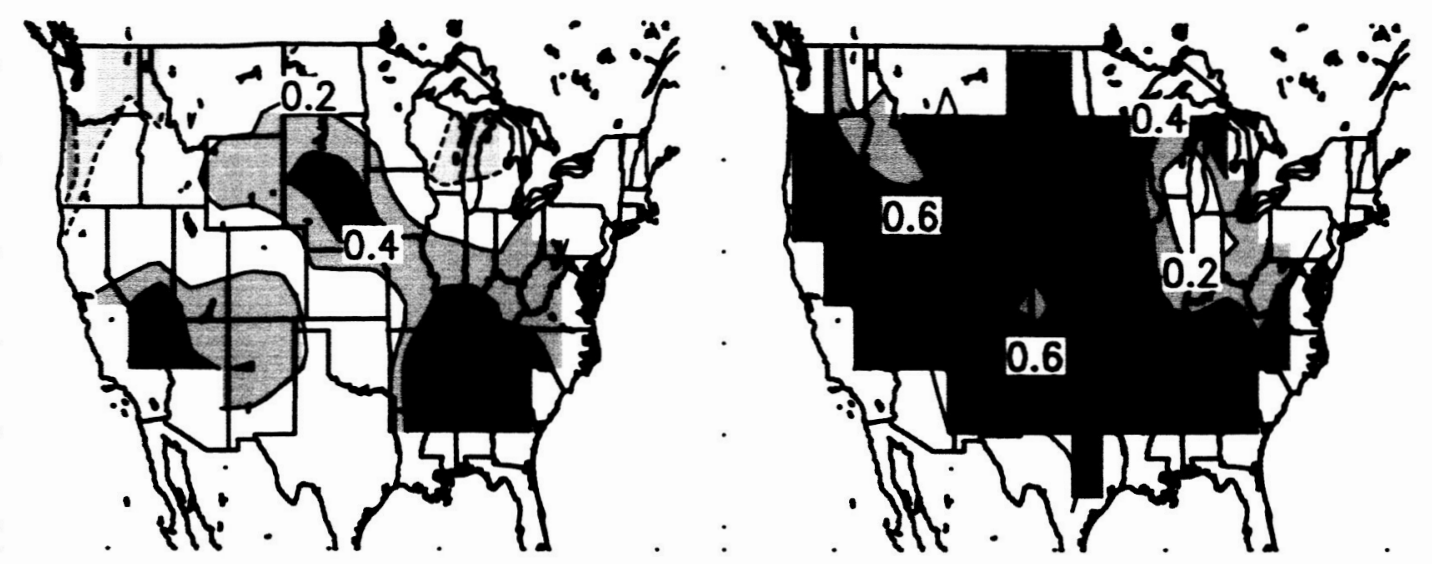

(b) gcm_rain, Jul

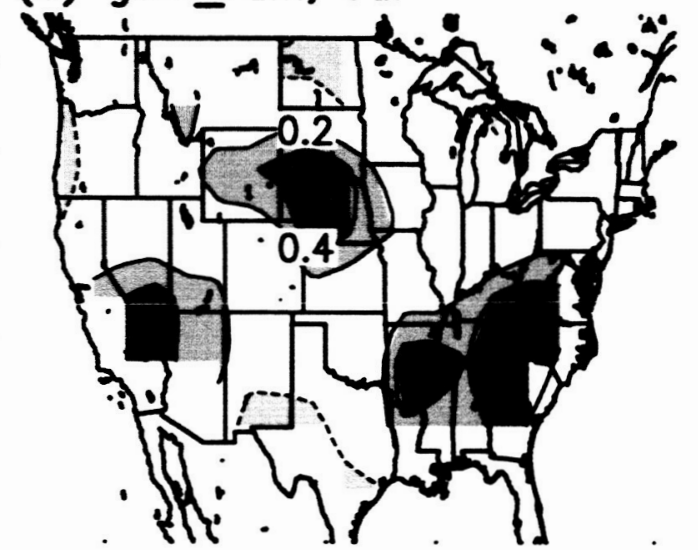

(e) obs_rain, Jul

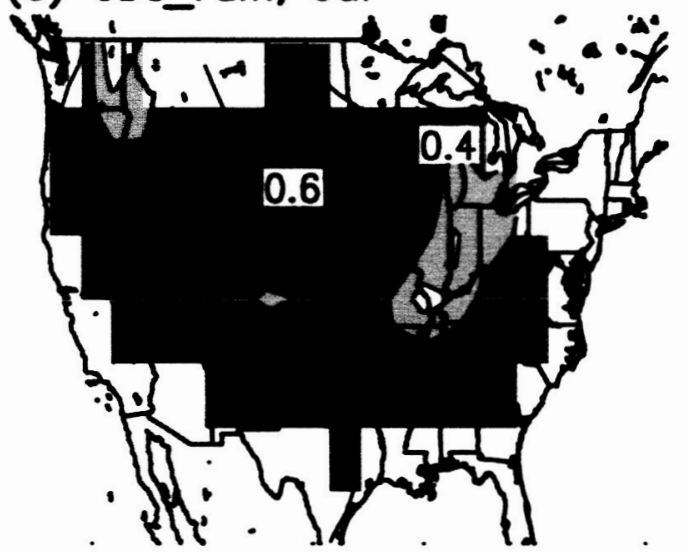

(c) gcm_rain, Aug

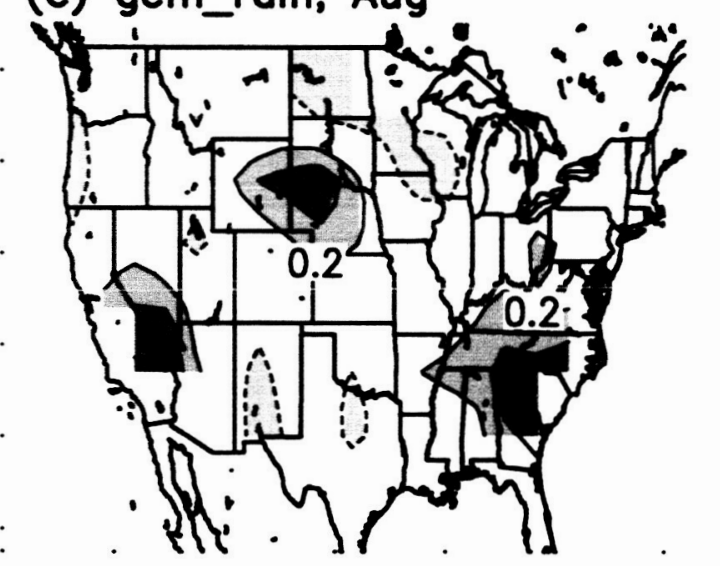

(f) obs_rain, Aug
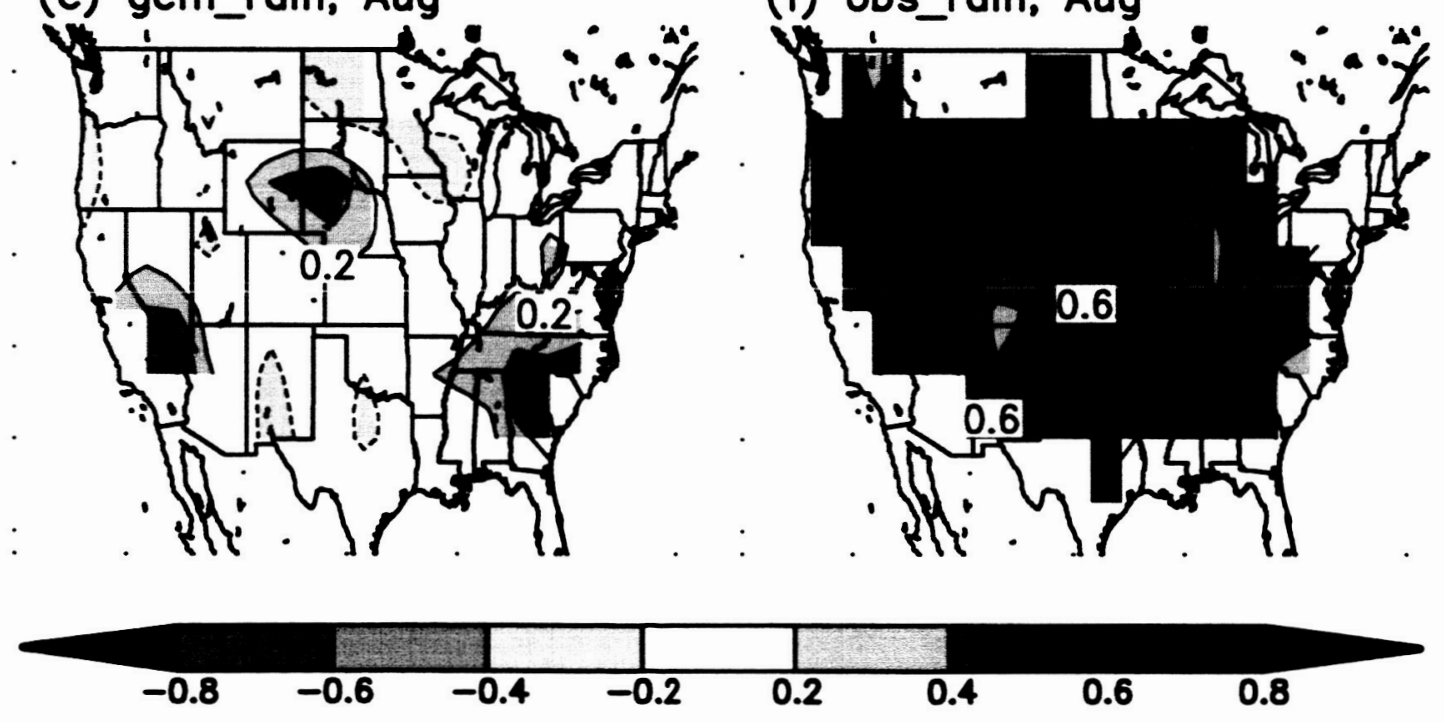

Figure 5. Same as in Figure 4, except for local correlations. 

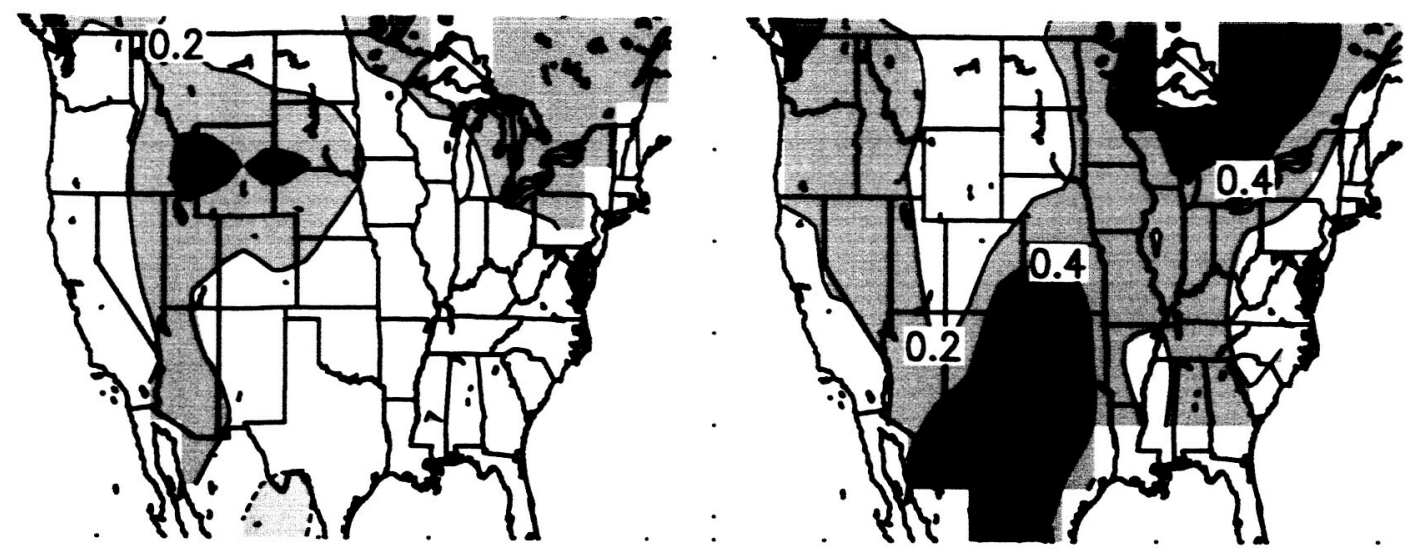

(b) gcm_rain, Jul

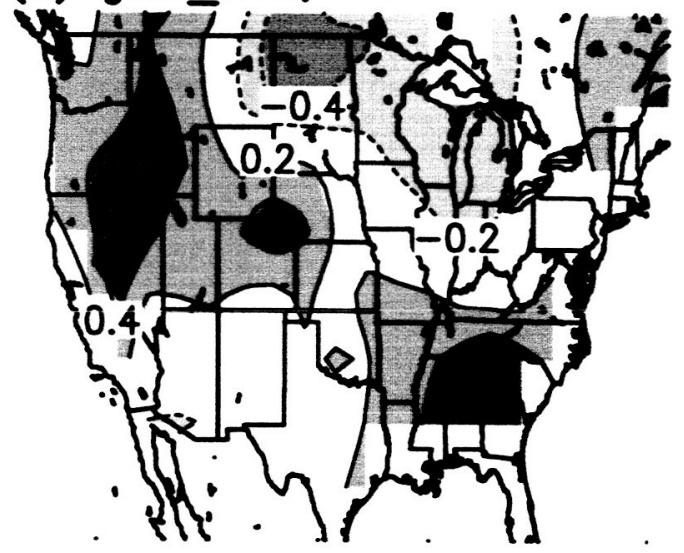

(e) obs_rain, Jul

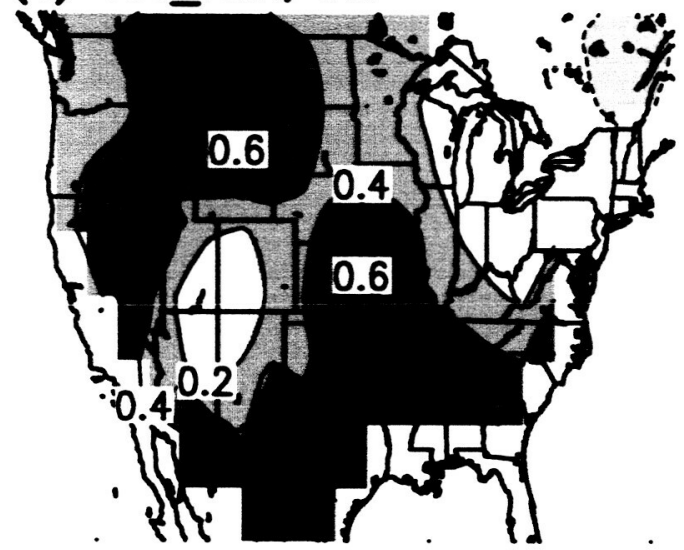

(c) gcm_rain, Aug

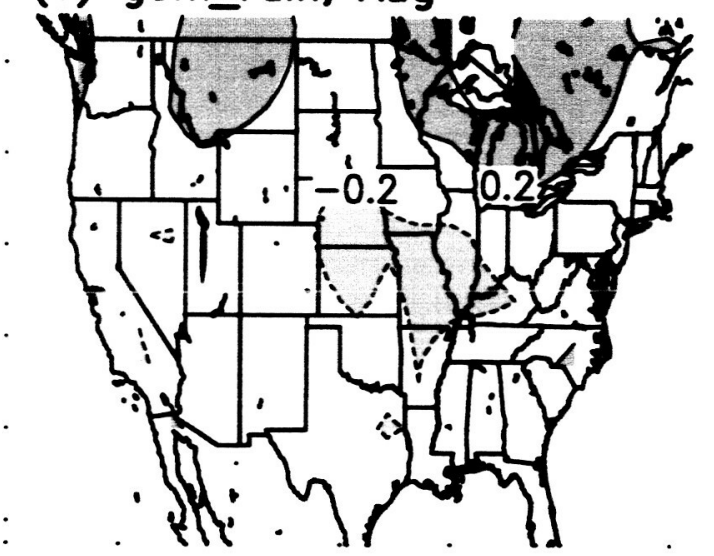

(f) obs_rain, Aug
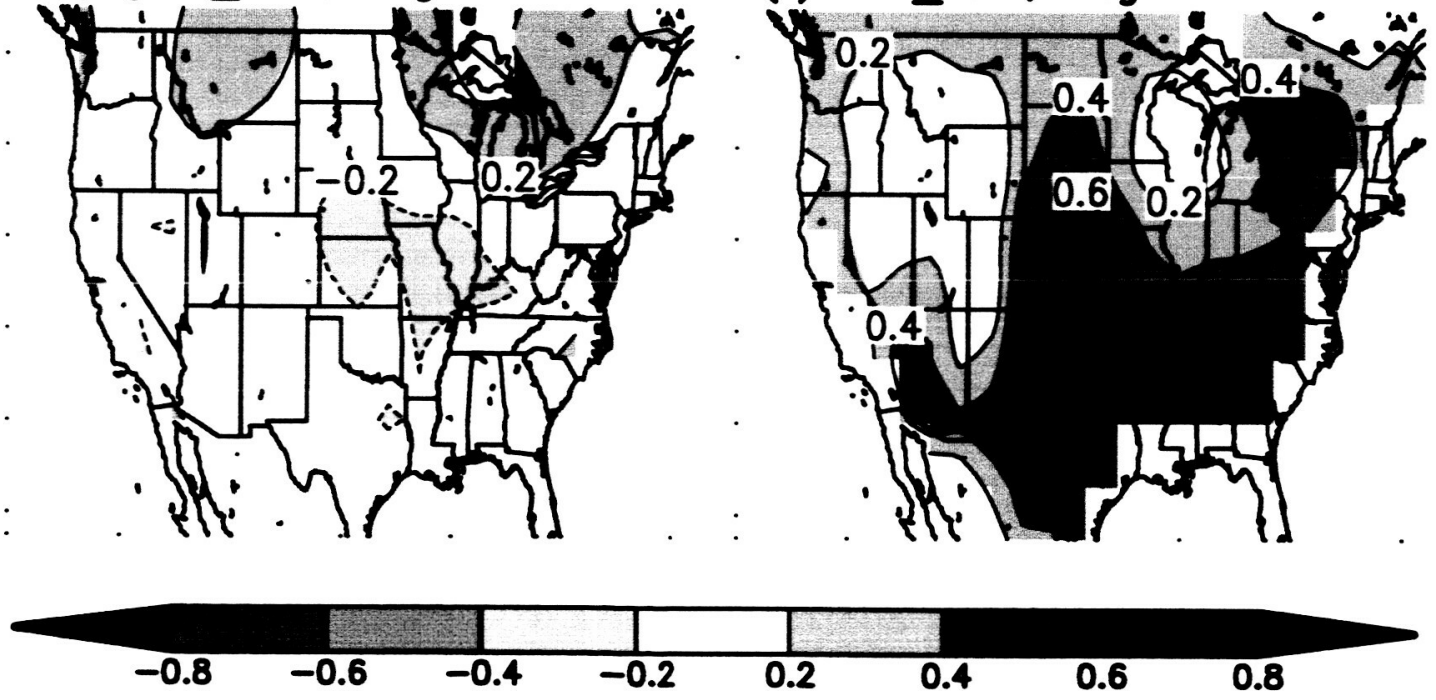

Figure 6. Local correlations of surface-air temperature between the GCM simulations and the CAMS observations in June, July and August averaged for the 1979-2000 period. Left panels are for the gcm_rain runs, and right panels are for the obs_rain runs. 

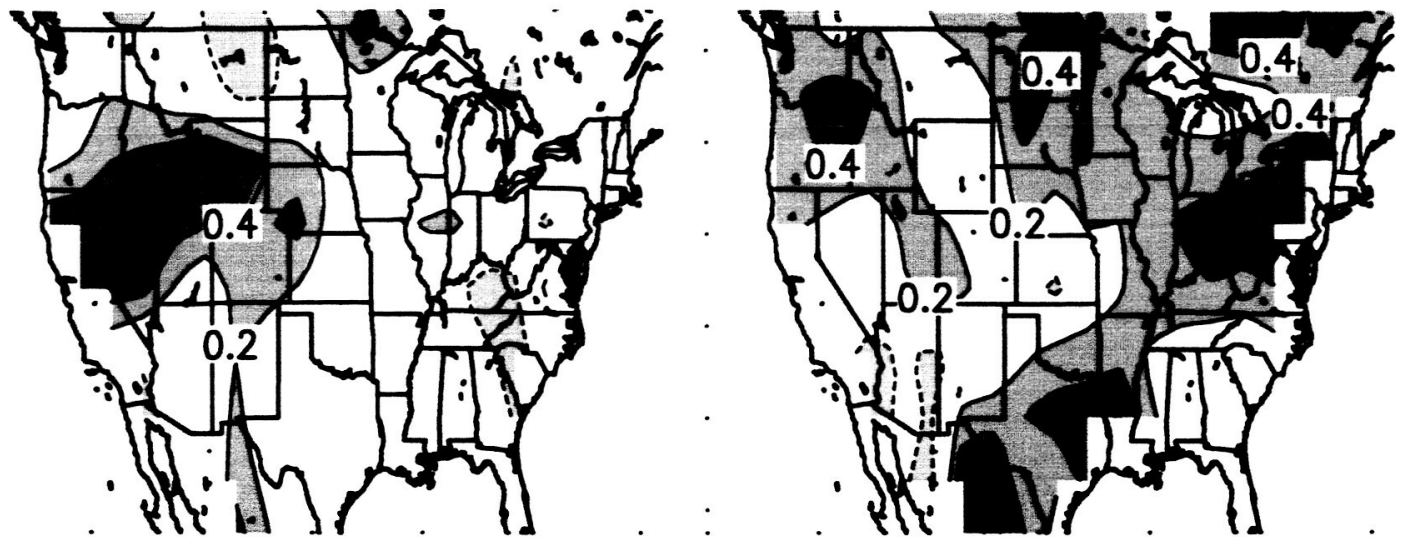

(b) gcm_rain, Jul

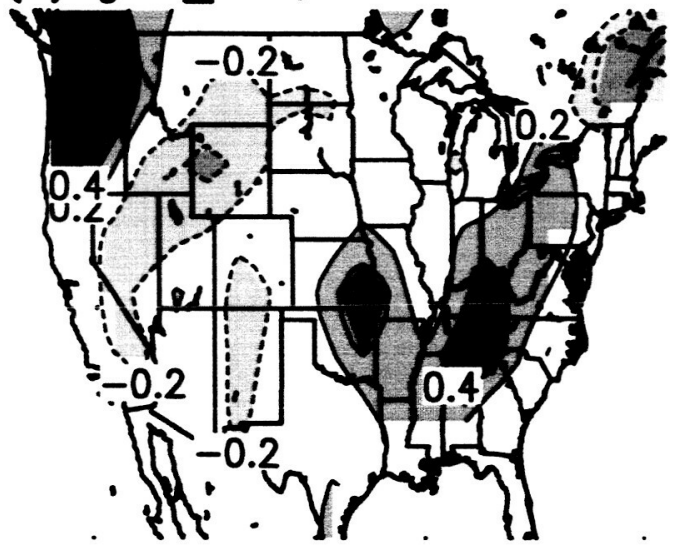

(e) obs_rain, Jul

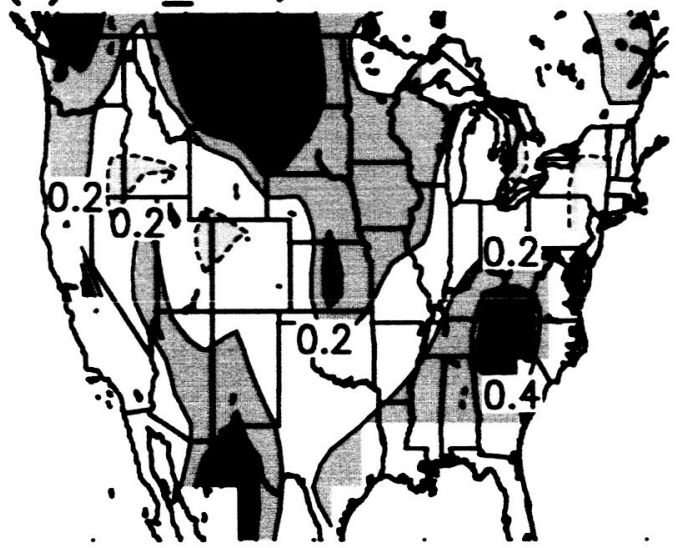

(c) gcm_rain, Aug

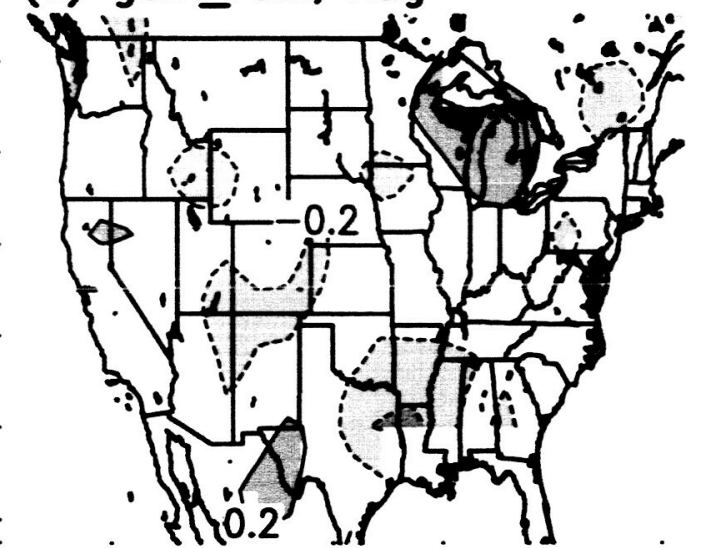

(f) obs_rain, Aug
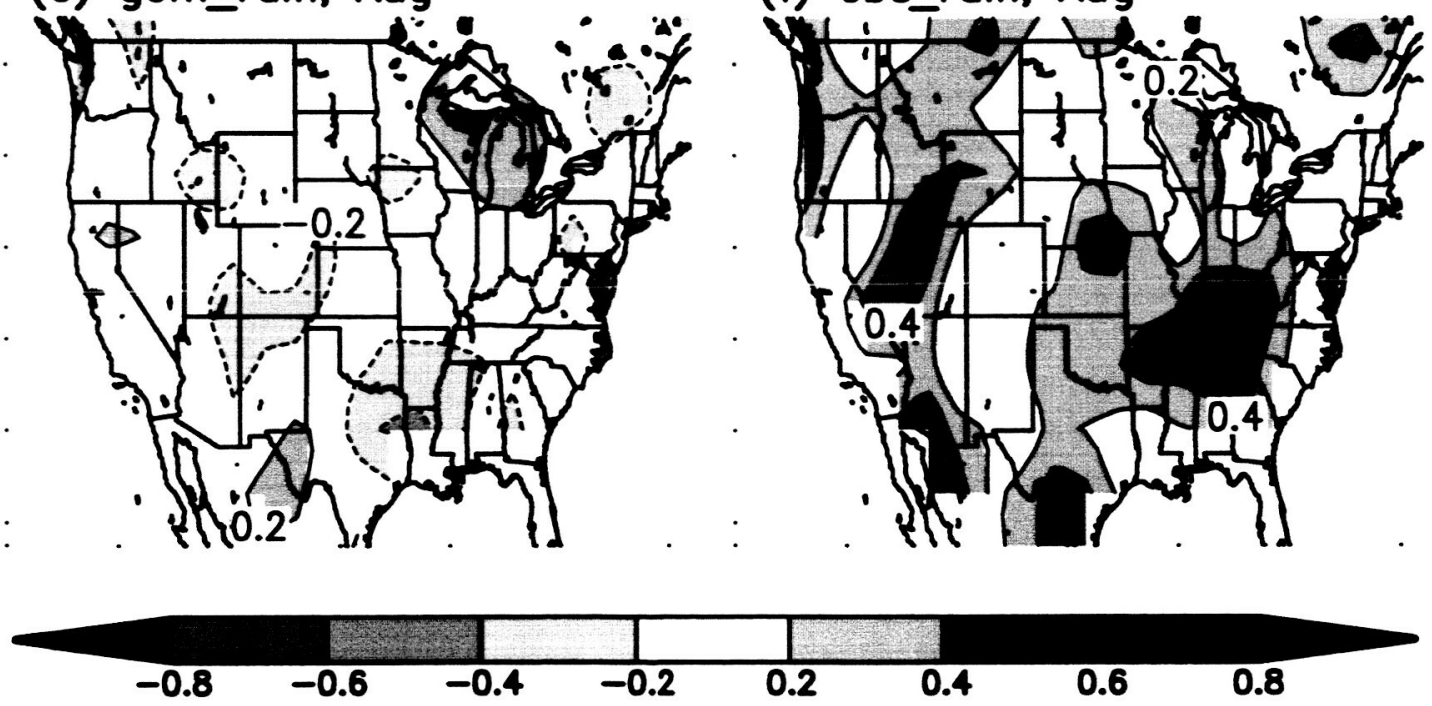

Figure 7. Local correlations of precipitation between the GCM simulations and the GPCP observations in June, July and August averaged for the 1979-2000 period. Left panels are for the $\mathbf{g c m}$ _rain runs, and right panels are for the obs_rain runs. 

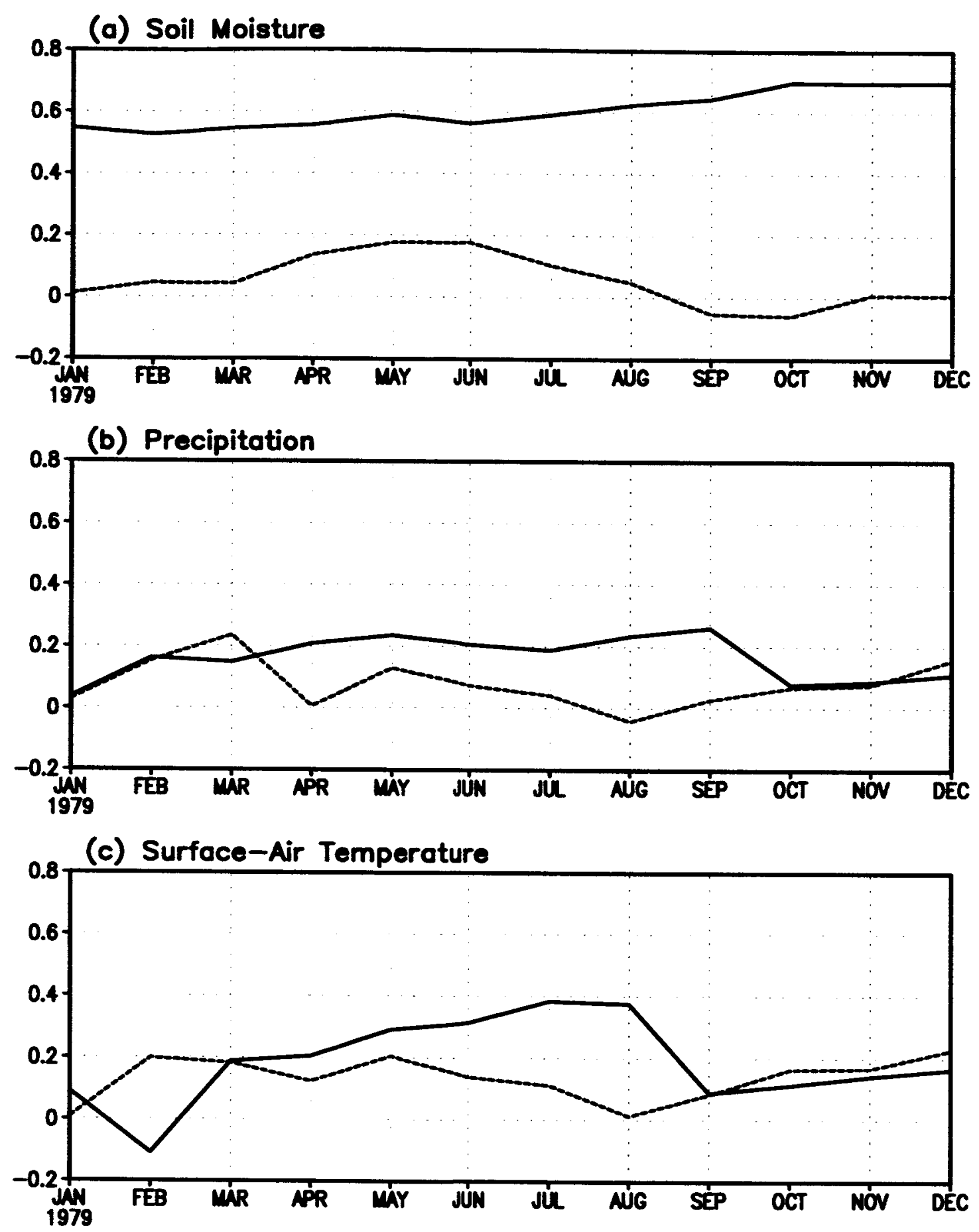

Figure 8. Mean correlations averaged over the entire US continents, for (a) soil moisture, (b) precipitation, and (c) surface-air temperature, as shown in Figures 5-7 except for all months. Dotted lines are for the correlations between the gcm_rain runs and observations, and bold lines are for those between the obs_rain runs and observations. 

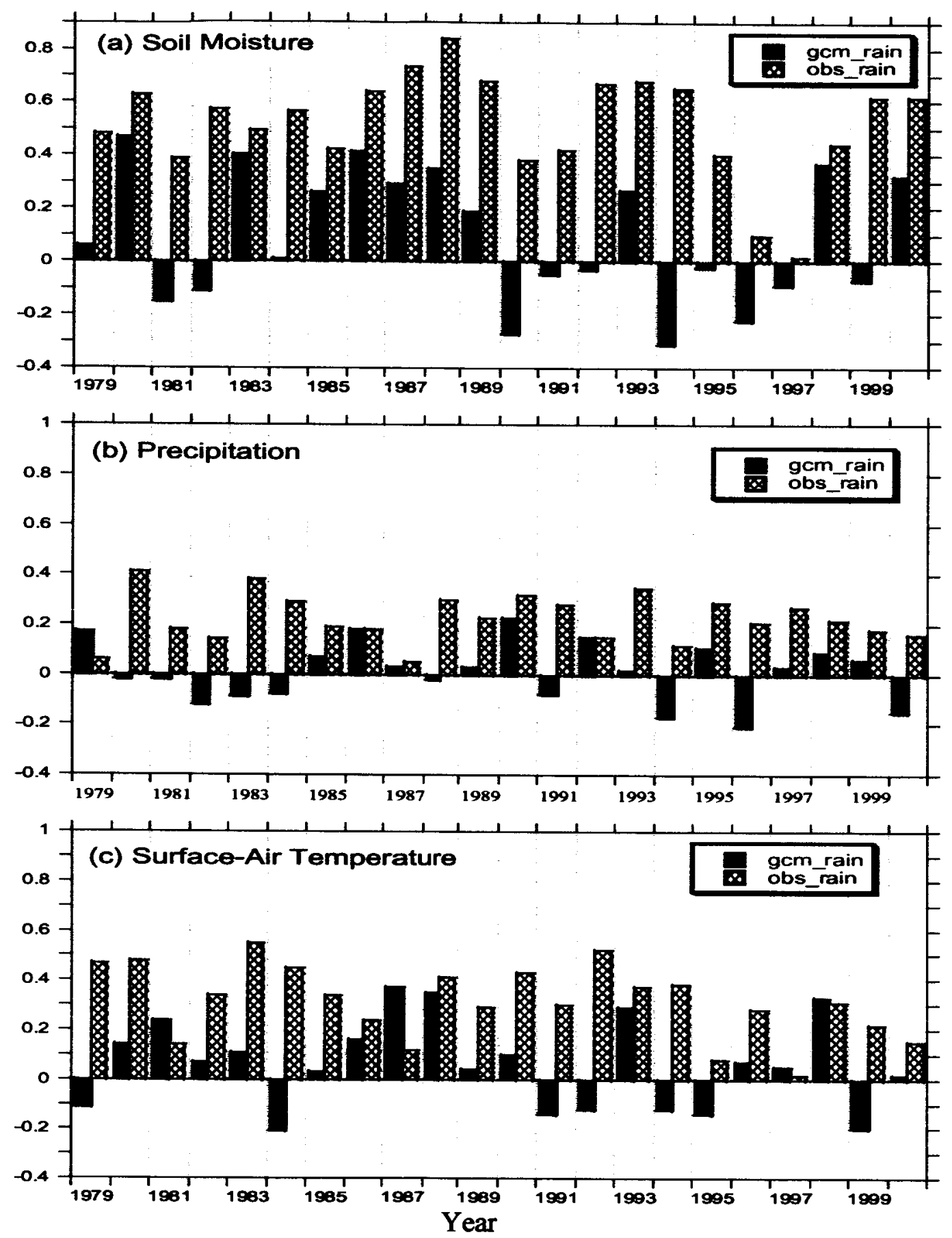

Figure 9. Pattern correlations of June-July-August mean anomalies for (a) soil moisture, (b) precipitation, and (c) surface-air temperature over the US continent from 1979 through 2000 between the NCEP GCM simulations and the observations as described in the text. Solid bars are for the $\mathrm{gcm}$ rain runs for which precipitation assimilation was not applied. Cross bars are for the obs_rain runs for which the observed GPCP pentad-mean precipitation was used to force the land-surface component of the GCM. 